Reprod. Nutr. Dévelop., 1986, 26 (1 B), 361-362.

\title{
Modifications des lipoprotéines plasmatiques associées à lá stéatose hépatique chez la vache en début de lactation
}

\author{
Y. RAYSSIGUIER, A. MAZUR, I. M. REID (*), C. J. ROBERTS $\left({ }^{*}\right)$, Elyett GUEUX \\ I.N.R.A. Theix, 63122 Ceyrat, France. \\ ${ }^{*}{ }^{*}$ A.R.C. Compton, Nr Newbury, Berkshire RG 16 ONN, U.K.
}

Summary. LDL phospholipid and cholesterol levels were significantly decreased in cows with severe fatty liver at one week post-calving compared to control animals at the same period.

Chez la vache laitière en début de lactation, la lipomobilisation est à l'origine d'une stéatose hépatique (Reid et Roberts, 1983) qui ne peut s'expliquer entièrement par l'augmentation du prélèvement des acides gras libres et par leur réestérification puisque les lipides sont normalement sécrétés sous forme de lipoprotéines associant triglycérides, phospholipides et cholestérol. L'étude de la répartition des lipides dans les différentes classes de lipoprotéines devrait permettre une meilleure compréhension de l'infiltration lipidique du foie.

Matériel et méthodes. Des biopsies hépatiques ont été réalisées de 7 à 13 jours après vêlage chez des vaches Frisonnes (moyenne de $6480 \mathrm{~kg}$ pour la lactation précédente) provenant des troupeaux expérimentaux de l'ARC à Compton. Après la mise en œuvre de techniques histologiques, le pourcentage d'infiltration lipidique a été déterminé par analyse morphométrique, ce qui a permis de répartir les animaux selon le degré d'infiltration lipidique (inférieur à $20 \%$ pour le lot témoin et supérieur à $40 \%$ pour le lot sévèrement stéatosique, 6 vaches par lot). Un prélèvement sanguin a été effectué sur toutes les vaches à la date de la biopsie et 4 semaines après le vêlage chez les vaches du lot témoin. Les lipoprotéines de très faible densité (VLDL), faible densité (LDL) ont été séparées par ultracentrifugation aux densités de 1,006, 1,063 et 1,21 $\mathrm{g} / \mathrm{ml}$. Des techniques enzymatiques ont permis la détermination des taux de triglycérides, de cholestérol et de phospholipides plasmatiques, ainsi que la répartition du cholestérol et des phospholipides dans les différentes classes des lipoprotéines.

Résultats et discussion. Chez les vaches témoins, le début de la lactation, comparé à la $4^{\mathrm{e}}$ semaine, se caractérise au niveau plasmatique par de faibles valeurs du cholestérol et des phospholipides en particulier, dans la fraction LDL (tabl.1). Les taux de triglycérides ne sont pas modifiés, en accord avec des résultats précédents (Mazur et al., 1986).

Chez les vaches stéatosiques, en début de lactation, les taux de cholestérol et de phospholipides de la fraction LDL sont inférieurs, respectivement, de 39 et $50 \%$ par rapport aux valeurs obtenues chez les vaches témoins ; les taux plasmatiques de triglycérides ne sont pas modifiés $117,0 \pm 3,7$ vs $17,9 \pm$ $0,8 \mathrm{mg} / 100 \mathrm{ml}$ ). Le début de la lactation est donc associé à un faible taux de LDL 
TABL. 1. - Influence du début de la lactation et de la stéatose hépatique sur les valeurs du cholestérol et des phospholipides dans le plasma et les lipoprotéines chez la vache.

\begin{tabular}{llllll}
\hline & & Plasma & VLDL & LDL & HDL \\
\hline \multirow{3}{*}{ Cholestérol } & Lot témoin A & $109,0 \pm 2,4$ & $<1$ & $12,9 \pm 1,2$ & $86,9 \pm 1,6$ \\
& Lot stéatosique A & $101,3 \pm 4,5$ & $<1$ & $7,9 \pm 0,8^{* *}$ & $86,7 \pm 5,7$ \\
& Lot témoin B & $220,0 \pm 13,5$ & $<1$ & $50,9 \pm 8,9$ & $132,7 \pm 8,4$ \\
\hline \multirow{3}{*}{ Phospholipides } & Lot témoin A & $139,5 \pm 4,8$ & $<1$ & $10,7 \pm 1,3$ & $93,9 \pm 3,1$ \\
& Lot stéatosique A & $109,5 \pm 4,9^{* *}$ & $<1$ & $5,4 \pm 0,7^{* *}$ & $80,1 \pm 5,0^{*}$ \\
& Lot témoin B & $276,2 \pm 19,2$ & $<1$ & $73,8 \pm 16,1$ & $144,0 \pm 8,2$ \\
\hline
\end{tabular}

$A=1$ semaine ; $B=4$ semaines après le vêlage. Les valeurs exprimées en $\mathrm{mg} / 100 \mathrm{ml}$ sont les moyennes \pm erreur type de 6 animaux. ${ }^{*} \mathrm{P}<0,05{ }^{* *} \mathrm{P}<0,01$. Comparaison du lot témoin et stéatosique à 1 semaine.

et, sous réserve du petit nombre d'animaux étudiés, cette expérimentation est la première à mettre en évidence une accentuation de ce phénomène chez les vaches stéatosiques. Cette observation est à rapprocher des résultats récents de Herdt et al. (1983) obtenus par précipitation des lipoprotéines légères chez des animaux stéatosiques présentant une torsion de la caillette. La diminution des LDL pourrait refléter une diminution de la sécrétion des lipoprotéines et, les triglycérides étant normalement associés au cholestérol et aux phospholipides, les résultats pourraient suggérer une difficulté particulière de la synthèse de ces constituants lipidiques. Le dosage du cholestérol et des phospholipides associés aux LDL pourrait donc constituer, à l'avenir, un critère de choix dans le diagnostic des formes subcliniques de stéatose hépatique.

Herdt T. H., Liesman J. S., Gerloff B. J., Emery R. S., 1983. Reduction of serum triacylglycerolrich lipoprotein concentrations in cows with hepatic lipidosis. Am. J. vet. Res., 44, 293-296.

Mazur A., Gueux E., Chilliard Y., Rayssiguier Y., 1986. Evolution des lipides et lipoprotéines plasmatiques chez la vache en début de lactation. Reprod. Nutr. Dévelop., 26, 357-358.

Reid I. M., Roberts C. J., 1983. Subclinical fatty liver in dairy cows. Current research and future prospects. Irish Vet. J., 37, 104-110. 